\title{
Systemic Adverse Reaction to Specific Immunotherapy
}

Abdulghani Mohamad Alsamarai ${ }^{1 *}$, Amina Hamed Ahmad Alobaidi ${ }^{2}$, Amar Mohamad Alwan $^{3}$, Zainab Hashim Abdulaziz $^{4}$ and Zaid Mothana Dawood

${ }^{1}$ Tikrit University College of Medicine, Departments of Medicine, Iraq

${ }^{2}$ Tikrit University College of Medicine, Biochemostry, Iraq

${ }^{3}$ Tikrit University College of Medicine, Otolaryngology, Iraq

${ }^{4}$ Tikrit Teaching Hospital, Salahuldean Health Authority, Tikrit, Iraq

\begin{abstract}
Background: Allergen immunotherapy has been reported to be effective in reducing allergic symptoms and drug consumption in cases of respiratory allergy. However, some concerns still exist about the relative safety of allergen immunotherapy. This form of therapy has a potential risk of serious systemic reactions.
\end{abstract}

Objective: To evaluate the frequency of systemic reactions due to subcutaneous allergen immunotherapy in Iraq and to identify factors associated with increased risk of adverse systemic reaction.

Methods: From January 2000 to December 2008, we selected 693 patients with allergic rhinitis and asthma to receive subcutaneous specific immunotherapy. Prospective immunotherapy safety was evaluated by recording postinjection adverse effects. The adverse reaction observed during the administration of subcutaneous immunotherapy within a period of 9 years (2000-2008), was analyzed in this study.

Result: Data were obtained from 693 patients who received subcutaneous immunotherapy (SCIT). The mean number of skin tests positivity and number of injections were significantly higher in systemic reaction group compared to negative systemic reaction group. During the study period, a total of 39281 injections were administered to 693 patients. Of the 693 patients, $82(11.8 \%)$ had systemic reaction, with an incidence of 2.1/1000 injection. Sixty nine of the 82 systemic reaction (84\%) developed in the build up phase, versus $13(16 \%)$ in the maintenance phase $(p<0.0001)$, with respect to reaction time, $47(57 \%)$ of the systemic reaction were immediate (within 30 minutes respect to reaction time), and $35(43 \%)$ were delayed. There were higher significant influences of polysensitisation, age, asthma, combination of asthma and allergic rhinitis, type of allergen, and indoor allergens on the development of systemic adverse reactions to subcutaneous immunotherapy.

Conclusion: The present study suggests that SCIT was a safe treatment with a low risk to elicit severe systemic reaction, in which no fatality was observed. Furthermore, this study indicated that mold, HDM, asthma, presence of asthma and allergic rhinitis (AR), polysensitisation, and indoor allergens sensitization were a risk factors contributing to systemic reactions.

Keywords: Specific immunotherapy; Asthma; Allergic rhinitis; Risk factor; SCIT; Safety; Iraq; Tikrit

\section{Introduction}

Allergic diseases are commonly encountered medical condition that causes substantial morbidity and mortality worldwide. Avoidance of suspected allergens is a treatment for allergic conditions (allergic rhinosinusitis, asthma and allergic rhinitis) [1-3]. However, in many cases exposure to a particular allergen cannot be completely avoided. Available medical therapies are not always fully effective or well tolerated [4,5]. Allergen specific immunotherapy is treatment that an effective and well tolerated treatment approaches for allergic diseases [6]. Allergen specific immunotherapy is treatments that modifies the immunological response to allergens and induce a state of clinical tolerance [7]. Recent research has helped uncover the mechanisms by which allergen immunotherapy exerts its therapeutic effect paving the way for the development of safer more effective therapy for a wider of allergic diseases [8]. In consensus reports and meta-analyses, allergen immunotherapy has been reported to be effective in reducing allergic symptoms and drug consumption in cases of respiratory allergy due to pollens, mites, animal dander and moulds [9]. However, some concerns still exist about the relative safety of allergens immunotherapy. This form of therapy has a potential risk of serious systemic reactions, as it involves subcutaneous injection of allergen extracts to which the patients is sensitive [10]. Despite clear advances in the prevention of such reactions, varying rates of severs reactions have been reported since the introduction of standardized and more potent extracts [11-21].
The aim of this study was to evaluate the frequency of systemic reactions due to subcutaneous allergen immunotherapy in our country and to identify factors associated with increased risk of adverse systemic reaction.

\section{Material and Methods}

\section{Patients}

From January 2000 to December 2008, we selected 693 patients with allergic rhinitis and/ or asthma to receive subcutaneous specific immunotherapy according to European Academy of Allergy and Clinical Immunology (EAACI) guidelines [22]. All injections during the induction and maintenance were administered at an immunotherapy unit by consultant physician. Prospective, immunotherapy safety was evaluated by recording post-injection adverse effects. Written informed

Corresponding author: Prof. AGM Alsamarai, Tikrit University College of Medicine, Departments of Medicine, Tikrit, Salahuldean 12112, Iraq, E-mail: galsamarrai@yahoo.com, momoghsa@gmail.com

Received April 20, 2011; Accepted June 06, 2011; Published June 10, 2011

Citation: Alsamarai AM, Alobaidi AHA, Alwan AM, Abdulaziz ZH, Dawood ZM (2011) Systemic Adverse Reaction to Specific Immunotherapy. J Aller Ther 2:111. doi:10.4172/2155-6121.1000111

Copyright: (c) 2011 Alsamarai AM, et al. This is an open-access article distributed under the terms of the Creative Commons Attribution License, which permits unrestricted use, distribution, and reproduction in any medium, provided the original author and source are credited. 
consents were obtained from all patients (or their parents for children) before the initiation of immunotherapy and the guidelines were followed to monitor patients during allergen extract injection.

The adverse reaction observed during the administration of subcutaneous immunotherapy within a period of 9 years (20002008), was analyzed in this study. Demographic and clinical data and peak expiratory flow before and after injection were recorded by the investigators on a standardized form.

\section{Immunotherapy schedule}

Immunotherapy was given in term of conventional schedule. Conventional Immunotherapy build- up was typically given as injection per week until the maintenance dose was reached and it was given once monthly. Allergen vaccines were administered subcutaneously according to EAACI guidelines [23] after the patients had given their informed consent. The standard schedule is presented in Table 1. However, for patients with systemic reactions [if he developed systemic reactions following the first injection] the starting dose is reduced to $0.01 \mathrm{IR} / \mathrm{ml}$. The stock solution was with $10 \mathrm{IR} / \mathrm{ml}$ and to prepare starting dose solution, it was diluted as tenfold dilution for two times using phenol saline. Each allergen was in a separate vial.

\section{Adverse reactions to immunotherapy}

The adverse reactions to Immunotherapy were assessed according to EAACI classification [5] and systemic reaction was chosen as the main outcome measure. In order to neutralize any possible nocebo effect, grade 0 reactions (non specific symptoms) were excluded [12], local reactions were not considered. Reactions to immunotherapy were defined as immediate if they began within 20 minutes of injection; otherwise, they were termed late.

\section{Asthma and allergic rhinitis diagnosis}

The diagnosis of asthma and classification was performed by specialist physicians based on the National Heart Blood and Lung Institute/World Health Organization (NHLBI/WHO) workshop on the Global Strategy for Asthma [24]. Allergic rhinitis diagnosis was

\begin{tabular}{|c|c|c|}
\hline $\begin{array}{l}\text { CONCENTRATION } \\
\text { IR/ml }\end{array}$ & $\begin{array}{l}\text { VOLUME INJECTED } \\
(\mathrm{ml})\end{array}$ & WEEK \\
\hline 0.1 & $\begin{array}{l}0.1 \\
0.2 \\
0.4 \\
0.8\end{array}$ & $\begin{array}{l}1 \\
2 \\
3 \\
4\end{array}$ \\
\hline 1 & $\begin{array}{l}0.1 \\
0.2 \\
0.4 \\
0.8\end{array}$ & $\begin{array}{l}5 \\
6 \\
7 \\
8\end{array}$ \\
\hline 10 & $\begin{array}{l}0.1 \\
0.2 \\
0.4 \\
0.6 \\
0.8 \\
0.8 \\
0.8 \\
0.8 \\
0.8 \\
0.8 \\
0.8 \\
0.8\end{array}$ & $\begin{array}{c}9 \\
10 \\
11 \\
12 \\
13 \\
14 \\
15 \\
16 \\
17 \\
18 \\
19 \\
20\end{array}$ \\
\hline
\end{tabular}

A: INITIAL TREATMENT DOSES

For patients with systemic reactions, the treatment should start with $0.01 \mathrm{IR} / \mathrm{ml}$. B: MAINTENANCE DOSES

The maintenance dose was with $0.8 \mathrm{ml}$ of $10 \mathrm{IR} / \mathrm{ml}$.

Table 1: Immunization protocol performed according to previously reported guidelines [25]

\section{Lung function test}

Computerized Spirometer (Autosphiror, Discom-14, Chest Corporation, and Japan) was used for measurement of FEV1 predicted percent of the patients at their enrollment in the study and when indicated according to studies design.

\section{Skin prick test}

The skin prick tests were performed for all patients and control and evaluated in accordance with European Academy of Allergy and Clinical Immunology subcommittee on allergy standardization and skin tests using standards allergen panel (Stallergen, France). The panel for skin test include: dust mite (Dermatophagoides farina, Dermatophagoides peteronyssinus), Aleternaria, Cadosprium, Penicillum mixture, Aspergillus mixture, Grasses mixture, Feather mixture, Dog hair, Horse hair, Cat fur, Fagacae, Oleaceae, Betulaceae, Plantain, Bermuda grass, Chenopodium and Mugworth. All tests were performed in the outpatient Asthma and Allergy Centre, Mosul by a physicianusing a commertial allergen extracts (Stallergen, France) and a lancet skin prick test device. A wheal diameter of $3 \mathrm{~mm}$ or more in excess of the negative control was considered as positive test result.

\section{Allergen extracts for SCIT}

Therapeutic vaccines containing allergen extracts were purchased from Stallergen, France. Both aqueous and glycenerated extracts were used to achieve a starting dose concentration of $0.1 \mathrm{IU} / \mathrm{ml}$. The purchased stock solutions are at concentration of $0.1,1$ and $10 \mathrm{IU} / \mathrm{ml}$. In standardized extracts the stock formulation was prepared by tenfold dilution. Separate vial was used for allergen extract to reduce proteolysis degradation. All extracts were stored at $8^{\circ} \mathrm{C}$. Therapeutic vaccine varied with each individual patient based on specific allergen identified during testing. Moist patients received a variety of aeroallergen combination.

\section{SCIT protocol}

The treatment protocol is of two stage, the attack (build-up) and maintenance stages. The attack treatment with gradual increase in dose and concentration of vaccine content were carried weekly for a period of 20 weeks. The vaccine is injected by deep subcutaneous route in the posterior aspect of upper arm. The maintenance treatment dose given in a constant dose every 15 days and then every 4 or 6 weeks interval. The interval between two maintenance injections must not exceed 6 weeks. Local reaction size was measured 20 minutes after each injection. Observed large local reactions (more than $20 \mathrm{~mm}$ wheal size) mandated a repeat of the same dose on the next visit, while systemic allergic reactions (skin, respiratory, cardiovascular, and/or gastrointestinal) required a two-fold reduction in vaccine concentration. Maintenance dose was set in most cases at 0.5 of the stock standardized extracts.

\section{Statistical analysis}

Variables for analysis were selected from clinical variables based on results from another published studies and on clinical expert opinion $[5,9,26]$. Odd ratio was used to examine the relationship between each variable and systemic reaction to subcutaneous immunotherapy. The chi-square test was used to compare the clinical evaluation, skin prick test, and risk factor for development of systemic reaction. OR was calculated to determine the association between different risk factors and the development of systemic reaction. Discriminative power for risk relationship between allergens and probability of systemic reaction was assessed by a receiver operating characteristics (ROC) curve, which 
plotted the sensitivity of systemic reaction detection against the false positive across a threshold of probabilities. Statistical analysis was performed with a software package (SPSS, version.17).

\section{Results}

Data were obtained from 693 patients who received SCIT. Their demographic characteristics and clinical features are shown in Table 2. Their age range from 6 to 75 years with a mean age of $33 \pm 15$ year. There are no significant differences in age means between total patients group, patients group who developed systemic reactions and patients group without systemic reactions. Only 69 patients (10\%) of the study population demonstrate positive skin prick test to monoallergen. The mean number for skin test positivity was significantly higher $(\mathrm{P}<0.0001)$ in systemic reaction group $(7.6 \pm 3)$ compared to negative systemic reaction group $(3.5 \pm 2)$.

The mean total number of injections was significantly higher $(\mathrm{p}<0.0001)$ in systemic reactions positive group $(82.4 \pm 63.6)$ compared to systemic reactions negative group $(55.2 \pm 41.8)$. Of the total subjects included in the study, 291 (42\%) were male. Skin prick test was positive in $465(67.1 \%)$ patient, while $411(59.3 \%)$ patients were sensitive to HDM Table 3.

\begin{tabular}{|c|c|c|c|}
\hline Variable & Mean (SD) & No of patients & (\%) \\
\hline Age range & $6-75$ & & \\
\hline \multicolumn{4}{|l|}{ Age (year) } \\
\hline $\begin{array}{l}\text { Total mean age (SD) } \\
\text { Mean age group with systemic reactions } \\
\text { Mean age group without systemic reactions }\end{array}$ & $\begin{array}{l}33(15) \\
34(15.1) \\
33(14.8)\end{array}$ & & \\
\hline $\begin{array}{l}\text { Allergen positive (mean } \pm \text { SD) } \\
\text { Total } \\
\text { systemic reactions positive } \\
\text { systemic reactions negative }\end{array}$ & $\begin{array}{l}4(2.5) \\
7.6(3) \\
3.5(2)\end{array}$ & & \\
\hline $\begin{array}{l}\text { No. injection } \\
\text { Total } \\
\text { systemic reactions positive } \\
\text { systemic reactions negative }\end{array}$ & $\begin{array}{l}58.4(45.7) \\
82.4(63.6) \\
55.2(41.8)\end{array}$ & & \\
\hline $\begin{array}{l}\text { Sensitization } \\
\text { Mono } \\
\text { Poly }\end{array}$ & & $\begin{array}{l}69 \\
624\end{array}$ & $\begin{array}{l}10 \\
90\end{array}$ \\
\hline $\begin{array}{l}\text { Medical history } \\
\text { Allergic rhinitis and/or } \\
\text { Conjunctivitis and/or } \\
\text { Asthma }\end{array}$ & & $\begin{array}{l}596 \\
409 \\
235\end{array}$ & $\begin{array}{l}86 \\
59 \\
34\end{array}$ \\
\hline $\begin{array}{l}\text { Gender } \\
\text { Male } \\
\text { Female }\end{array}$ & & $\begin{array}{l}291 \\
402\end{array}$ & $\begin{array}{l}42 \\
58\end{array}$ \\
\hline
\end{tabular}

Table 2: Demographic and clinical characteristic of patients.

\begin{tabular}{|l|l|l|}
\hline Allergen & No positive skin test & Percent \\
\hline Mold & 465 & 67.1 \\
\hline HDM & 411 & 59.3 \\
\hline Grass & 168 & 24.2 \\
\hline Bermuda & 162 & 20.4 \\
\hline Trees & 135 & 18.2 \\
\hline Mugworth & 120 & 17.3 \\
\hline Chenopod & 99 & 14.3 \\
\hline Plantain & 87 & 12.6 \\
\hline Feather & 75 & 10.8 \\
\hline Cat & 72 & 10.4 \\
\hline Dog & 51 & 7.4 \\
\hline Horse & 15 & 2.2 \\
\hline
\end{tabular}

Table 3: Skin test sensitization.
During the study period, a total of 39281 injections were administered to 693 patients. Of the 693 patients, 82 (11.8\%) had systemic reaction, with an incidence of 2.1/1000 injection (Table 4).

Sixty nine of the 82 systemic reaction (84\%) developed in the build up phase, versus $13(16 \%)$ in the maintenance phase $(\mathrm{P}<0.0001)$, with respect to reaction time, $47(57 \%)$ of the systemic reaction were immediate, and $35(43 \%)$ were delayed [29 (83\%) of them were developed during the first hour after the injection]. The immediate systemic reactions were treated with parenterally injections of $200 \mathrm{mg}$ hydrocortisone, subcutaneous epinephrine and chlorphenaramine maleate intramuscular injection. While the subjects with late systemic reactions did not need medical treatment.

None of the developed systemic reactions had life threatening reactions. Four $(4.9 \%)$ of the systemic reactions were of grade 3 and 78 (95.1\%) were of grade 2. For total patients, systemic reactions were common in subject with mould sensitization $(68 / 82 ; 82.9 \%$; $9.81 \%$ of total patients), followed by $\operatorname{HDM}(62 / 82 ; 75.6 \% ; 8.95 \%$ of total patients) and trees $(32 / 82 ; 39 \% ; 4.62 \%$ of total patients) Table 5 . With respect to allergen type grouping, of the 15 patients with positive skin test to horse allergen, 6 patients developed systemic reactions. In Plantain skin positive test (87 patients), 22 patients developed systemic reactions and in Mugworth group only 30 patients developed systemic reaction from 120 patients who are skin positive test. There was significant difference in SRs between mite and mould $(\mathrm{P}<0.0001)$ compared to other allergens.

A 24 risk factors (Table $6 \& 7$ ) were analyzed for their association with development of systemic adverse reactions following SCIT. There were a non significant influences of gender $(\mathrm{OR}=1, \mathrm{p}=0.92)$, number of injections $(\mathrm{OR}=0.73, \mathrm{p}=0.47)$, dog allergen $(\mathrm{OR}=1.4, \mathrm{p}=0.37)$ and grass allergen $(\mathrm{OR}=1.5, \mathrm{p}=0.09)$ on the development of systemic reactions (Table-5). However, there were a higher significant influences of polysensitization $(\mathrm{OR}=9.65, \mathrm{p}=0.0001)$ and age $(\mathrm{OR}=4.2, \mathrm{p}=0.03)$ on

\begin{tabular}{|l|l|}
\hline Variable & Number or \% \\
\hline No. of total patients & 693 \\
\hline systemic reactions & 82 \\
\hline \% systemic reactions / patients & 11.8 \\
\hline \% systemic reactions / injection & 0.21 \\
\hline
\end{tabular}

Table 4: frequency of systemic adverse reaction to SCIT.

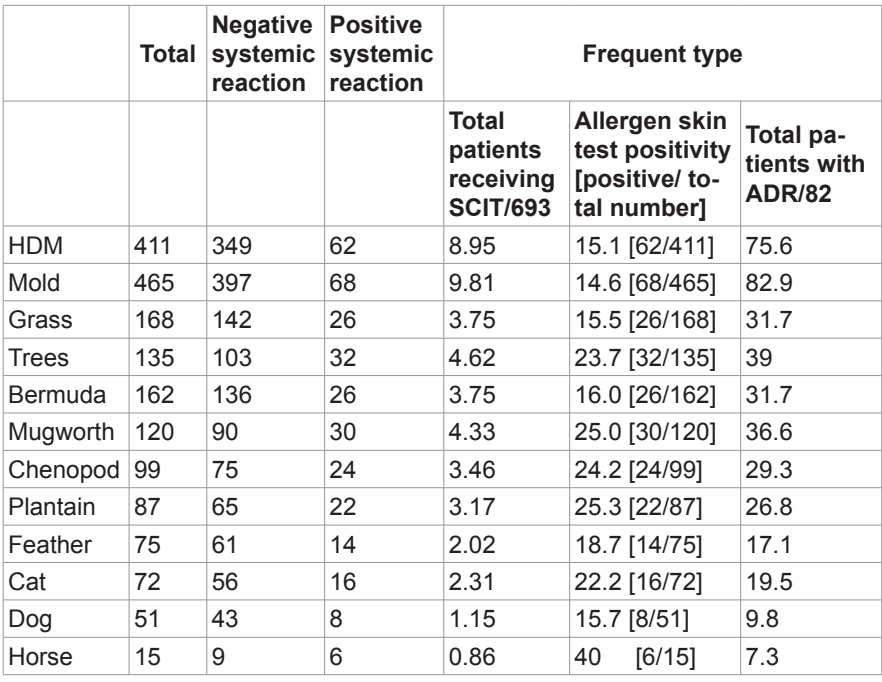

Table 5: Systemic reactions reaction in relation to allergen type. 
Citation: Alsamarai AM, Alobaidi AHA, Alwan AM, Abdulaziz ZH, Dawood ZM (2011) Systemic Adverse Reaction to Specific Immunotherapy. J Aller Ther 2:111. doi:10.4172/2155-6121.1000111

Page 4 of 7

the development of systemic reactions. Furthermore, asthmatic patients had greater tendency to have systemic reactions $(\mathrm{OR}=3.4, \mathrm{p}=0.017)$ and this tendency was increased when patients were with combined asthma and allergic rhinitis $(\mathrm{OR}=4.2, \mathrm{p}=0.003)$, Table 6 .

In addition, allergen type was with a predictive value for development of systemic adverse reactions. SCIT with horse allergen was a high risk factor $(\mathrm{OR}=5.3, \mathrm{p}=0.004)$ for development of systemic adverse reactions, followed by Trees $(\mathrm{OR}=3.5, \mathrm{p}=0.0001)$, Mugworth $(\mathrm{OR}=3.3, \mathrm{p}=0.0001)$, Plantain $(\mathrm{OR}=3.1, \mathrm{p}=0.0001)$, Chenopodium (OR=2.9, $\mathrm{p}=0.0001)$, Mould $(\mathrm{OR}=2.6, \mathrm{p}=0.0001)$, cat $(\mathrm{OR}=2.4$, $\mathrm{p}=0.003), \operatorname{HDM}(\mathrm{OR}=2.3, \mathrm{p}=0.0001)$, Bermuda $(\mathrm{OR}=2, \mathrm{P}=0.0007)$.

The systemic adverse reactions development was positively associated with patients sensitized to a specific combination of sensitization (data not shown). However, the number of patients in each group were small to give a validity for the statistical analysis. Patients who are sensitized to indoor allergens were more predominant to develop systemic reactions $(\mathrm{OR}=18.2, \mathrm{p}=0.0000)$ that who are sensitized to outdoor allergens $(\mathrm{OR}=2.9, \mathrm{p}=0.001)$. Furthermore, patients with polysensitisation to [HDM, Mold, Grass] were significantly $[\mathrm{P}=0.014]$ prone to develop systemic reaction to immunotherapy [OR $=3.04,95 \%$ CI 1.3-7.11].

The ROC curve demonstrating the trade-off between sensitivity and specificity for systemic reaction that results from various probability threshold indicated that area under the curve was $0.657\left(\mathrm{R}^{2}=0.90\right.$, $\mathrm{p}=0.001$ ), and the maximum discrimination point was a cut off probability of 0.0981 . This cut off point produced the following values indicating diagnostic utility: sensitivity 0.83 (95\% confidence interval 0.73-0.90); specificity, 0.64 (95\% CI 61-68); positive predictive value, 0.67 (95\% CI 0.63-0.71); negative predictive value, 0.94 (95\% CI 0.89 0.96); positive likelihood ratio, 1.27 (95\% CI 1.14-1.23) and negative likelihood ratio, 0.49 (95\% CI 0.3-0.79).

Regression analysis indicated a significant corrections between frequency of systemic adverse reactions in patients receiving SCIT and specificity $(\mathrm{r}=0.99, \mathrm{p}=0.000)$; and between frequency of systemic reactions and sensitivity $(\mathrm{r}=0.5, \mathrm{p}=0.001)$, in relation to different allergens immunotherapy. This indicated a close relationship between the predicted probability of systemic reactions and the prevalence of such reactions observed within each allergen group.

\begin{tabular}{|c|c|c|c|c|c|}
\hline \multicolumn{2}{|l|}{ Variable } & No. of patients & Systemic reaction (\%) & Odd ratio $(95 \% \mathrm{Cl})$ & $P$ value \\
\hline \multicolumn{2}{|l|}{$\begin{array}{l}0-14 \\
15-75\end{array}$} & $\begin{array}{l}60 \\
633\end{array}$ & $\begin{array}{l}3.3 \\
12.6\end{array}$ & $4.2(1-17.5)$ & 0.03 \\
\hline \multicolumn{2}{|l|}{$\begin{array}{l}\text { Gender } \\
\text { Female } \\
\text { Male }\end{array}$} & $\begin{array}{l}402 \\
291\end{array}$ & $\begin{array}{l}11.9 \\
11.7\end{array}$ & $1(0.6-1.6)$ & 0.92 \\
\hline \multicolumn{2}{|c|}{ Positive no. of allergen (skin prick test) } & $\begin{array}{l}360 \\
333\end{array}$ & $\begin{array}{l}2.8 \\
21.6\end{array}$ & 9.65(4.9-19.1) & $<0.0001$ \\
\hline \multicolumn{2}{|l|}{$\begin{array}{l}1-20 \\
21-\end{array}$} & $\begin{array}{l}66 \\
627\end{array}$ & $\begin{array}{l}9.1 \\
12.1\end{array}$ & $0.73(0.3-1.7)$ & 0.47 \\
\hline Skin test to HDM & Negative positive & $\begin{array}{l}282 \\
411\end{array}$ & $\begin{array}{l}7.1 \\
15.1\end{array}$ & 2.3(1.4-3.9) & 0.0001 \\
\hline Mold & Negative Positive & $\begin{array}{l}228 \\
465\end{array}$ & $\begin{array}{l}6.1 \\
14.6\end{array}$ & $2.6(1.4-4.8)$ & 0.0001 \\
\hline Grass & Negative Positive & $\begin{array}{l}525 \\
168\end{array}$ & $\begin{array}{l}10.7 \\
15.5\end{array}$ & $1.5(0.9-2.5)$ & 0.09 \\
\hline Trees & Negative Positive & $\begin{array}{l}558 \\
135\end{array}$ & $\begin{array}{l}8.2 \\
23.7\end{array}$ & $3.5(2.1-5.6)$ & $<0.0001$ \\
\hline Bermuda & Negative Positive & $\begin{array}{l}631 \\
162\end{array}$ & $\begin{array}{l}8.9 \\
16.0\end{array}$ & $2(1.2-3.2)$ & 0.007 \\
\hline Mugworth & Negative Positive & $\begin{array}{l}573 \\
120\end{array}$ & $\begin{array}{l}9.1 \\
25.0\end{array}$ & $3.3(2-5.5)$ & $<0.0001$ \\
\hline Chenopod & Negative Positive & $\begin{array}{l}594 \\
99\end{array}$ & $\begin{array}{l}9.8 \\
24.2\end{array}$ & $2.9(1.7-5)$ & $<0.0001$ \\
\hline Plantain & Negative Positive & $\begin{array}{l}606 \\
87\end{array}$ & $\begin{array}{l}10.0 \\
25.3\end{array}$ & $3.1(1.8-5.3)$ & $<0.0001$ \\
\hline Feather & Negative Positive & $\begin{array}{l}618 \\
75\end{array}$ & $\begin{array}{l}11.0 \\
18.7\end{array}$ & $1.8(1-3.5)$ & 0.05 \\
\hline Cat & Negative Positive & $\begin{array}{l}621 \\
72\end{array}$ & $\begin{array}{l}10.6 \\
22.2\end{array}$ & $2.4(1.3-4.4)$ & 0.003 \\
\hline Dog & Negative Positive & $\begin{array}{l}642 \\
51\end{array}$ & $\begin{array}{l}11.5 \\
15.7\end{array}$ & $1.4(0.6-3.2)$ & 0.37 \\
\hline Horse & Negative Positive & $\begin{array}{l}678 \\
15\end{array}$ & $\begin{array}{l}11.2 \\
40.0\end{array}$ & $5.3(1.8-15.2)$ & 0.004 \\
\hline
\end{tabular}

Table 6: Risk factor for systemic reaction during subcutaneous immunotherapy.

\begin{tabular}{|c|c|c|c|c|c|c|}
\hline Allergen origin & \multicolumn{2}{|c|}{ Patients number } & Patients No. & Percent & Odd ratio $[95 \% \mathrm{Cl}]$ & $P$ value \\
\hline Indoor & 580 & $\begin{array}{c}\text { Negative } \\
\text { Positive }\end{array}$ & $\begin{array}{c}499 \\
81\end{array}$ & $\begin{array}{l}81.7 \\
98.8\end{array}$ & $\begin{array}{c}18.2 \\
{[2.5-132]}\end{array}$ & 0.0000 \\
\hline Outdoor & 443 & $\begin{array}{c}\text { Negative } \\
\text { Positive }\end{array}$ & $\begin{array}{c}436 \\
7\end{array}$ & $\begin{array}{l}71.4 \\
87.8\end{array}$ & $\begin{array}{c}2.9 \\
{[1.5-5.7]}\end{array}$ & 0.001 \\
\hline
\end{tabular}

Table 7: Allergen origin as a risk factor for systemic reaction development to subcutaneous immunotherapy. 


\section{Discussion}

The occurrence of adverse systemic reaction due to allergen immunotherapy remains a major problem for both patients and clinicians [11]. Despite many preventive measures against systemic reactions, there is no proven predictive factor the appearance, type and severity of reaction [11]. In the present study we could not find any influence of gender and number of injections upon the development of adverse systemic reactions.

Previous studies have documented several risk factors for systemic reactions to immunotherapy $[27,28]$, but multiple sources of risk information may be variable geographically. Some reports have shown a higher frequency of adverse reactions in children than in adults $[29,30]$. However, in our study, there were more systemic reactions in patients over 14 years of age, a finding consistent with that reported by others [12]. The high frequency of systemic adverse reactions to immunotherapy may be due to immunological shift to the type 2 helper cell pattern and irreversible tissue lesions as a result of long disease duration in adults [12]

In reported studies [11,19,31], asthma is an important critical risk factor in the development of systemic and fatal reactions in immunotherapy. In the present study, all asthmatic patients were stable and under treatment. However, asthmatic had significantly higher rate of systemic reactions $(\mathrm{OR}=3.2, \mathrm{p}=0.017)$ than those with allergic rhinitis alone $(\mathrm{OR}=0.29)$ and tendency to develop SRs was increased in patients with combined asthma and allergic rhinitis $(\mathrm{OR}=4.2, \mathrm{p}=0.003)$. Our findings are consistent with the literature, in terms of increased incidence of SRs in asthmatic [11,19,31-35].

In a recent study, it was reported that most of the fatalities occurred in asthmatic with poor optimal control $[20,36]$. In contrast, to our findings other studies found no increase in the rate or severity of reactions in asthmatic patients [12,37]. According to our results and that reported by others [11], it should be suggested that even stable, well controlled asthmatic patients are prone to higher risk for systemic reactions. In a recent reported study [38], systemic reactions were predominant in patients with allergic rhinitis. However, Ragusa, et al. [39] reported higher incidence of SRs in patients with combined asthma and urticaria.

The variation in incidence of development of systemic reactions probably due to selection of patients for immunotherapy, the exclusion of uncontrolled asthmatic patients, and allergen type and source.

Regarding the type of allergen extract, Mould and HDM allergic patients, experienced systemic reactions more frequently compared to other inhalant allergens. However, the analysis of each inhalant allergen alone indicated that Grass, Feather and dog were not a risk factor for systemic reactions development during immunotherapy. Both Mould and HDM allergens systemic reactions development rates were significantly different $(\mathrm{p}<0.0001)$ from other inhalant allergens evaluated in this study. This finding was in consistent with some studies [19,32,40,41] and not with others [42]. Indoor allergens were a significant risk factor for development of systemic reactions to subcutaneous immunotherapy [OR=18.2, $\mathrm{P}<0.0001]$. In addition, polysensitisation do influence the susceptibility of patients to develop systemic reactions following immunotherapy.

Although, this study indicated that polysensitisation to inhalant allergens may act as risk factor for systemic reaction development during immunotherapy. A specific pattern of combination was act as risk factor for systemic reactions development. From 9 patients with polysensitisation for 3 allergens, only one [11\%] combination [HDM, Mold and Grass] may be considered as risk for development of systemic reactions during immunotherapy. In contrast, from 7 patients with polysensitisation for 4 allergens, 4 [57\%] combinations may be considered as a risk factor for systemic reactions development. Furthermore, all combinations of 5 and 6 allergens were significant risk factors for systemic reactions development during immunotherapy. The polysensitisation may act as a risk factors by converting TH1/TH2 imbalance, in favor of $\mathrm{TH} 2$ and this may be basically due to increase in allergen load and type.

This study indicated that the development of systemic reactions was higher during the build-up-phase of immunotherapy. These observations confirm previous reports indicating that most systemic reactions occurred during the dose build-up-phase of immunotherapy $[33,36,37]$. However, Moreno et al, found similar rated of systemic reactions in both build-up dosing and maintenance phases of immunotherapy [32]. Furthermore, recently it was reported that most fatal reactions had developed with maintenance allergen doses [20].

The frequency of systemic reactions development was more as immediate reaction (57\%). A finding consistent with that reported by others $[9,35,41]$ and not agreed with results of others $[11,19,42$ 44]. Although more than half of systemic reactions cases developed as immediate reactions, our results indicated an important aspect of development of $43 \%$ of systemic reactions were of late onsets. However, $83 \%$ of the assigned late reactions were developed in the period 25 minutes to 60 minutes after the injection. The most recent immunotherapy guidelines recommend a waiting period of 20-30 minutes after injection [5]. Although severe SRs usually appear within 30 minutes after injection, as we found in our study still there was high rate of patients can experience late onset systemic reactions. Thus we suggest that the observation of vaccinated patients should be extended more than 30 minutes in some patient settings, such as those with mold and/or HDM sensitization.

The frequency of development of SRs was $11.8 \%$ per patients, and this rate was lower to that reported by others $[11,38,43,45]$. However, our study finding SRs rate was higher than other reported studies $[13,39,42,44]$.

The reported rate of systemic reactions per injection has been variable from $0.06 \%$ to $2.033 \%[9,11,13,19,31,32,35,39,42-47]$. Our frequency of SRs was $0.21 \%$ and within the range reported by several studies. Furthermore our study indicated that development of SRs was lower in SCIT as compared to cluster and rash immunotherapy $[9,11,35,48-51]$. Thus the treatment with SCIT in asthma and allergic rhinitis were convenient for the patients even without premedication as this study indicated. Pretreatment with antihistamines has been proposed as an effective approach to reduce the side effects of immunotherapy [52]. There are controversial findings regarding the influence of antihistamine pretreatment on the occurrence of systemic allergic symptoms during allergen immunotherapy. Some studies indicated that pretreatment with antihistamine lead to a reduction in occurrence of systemic reactions following immunotherapy [52-57]. In contrast, other studies [58,59] observed no significant decrease of systemic reactions with the premedication use of antihistamines. It worth mentioning that antihistamine pretreatment does reduce systemic reactions without influencing the efficacy of immunotherapy [57].

In conclusion, the present study suggests that SCIT was a safe treatment with a low risk to elicit severe systemic reaction, in 
Citation: Alsamarai AM, Alobaidi AHA, Alwan AM, Abdulaziz ZH, Dawood ZM (2011) Systemic Adverse Reaction to Specific Immunotherapy. J Aller Ther 2:111. doi:10.4172/2155-6121.1000111

Page 6 of 7

which no fatality was observed. Furthermore, this study indicated that mold, HDM, asthma, presence of asthma and allergic rhinitis, polysensitisation, and indoor allergens sensitization were a risk factors contributing to systemic reactions.

\section{References}

1. Blaiss MS (2010) Allergic rhinitis: direct and indirect costs. Allergy Asthma Proc. 31: $375-380$

2. Broide DH (2010) Allergic rhinitis: pathophysiology. Allergy Asthma Proc. 31: 370-374.

3. Bernstein JA (2010) Allergic and mixed rhinitis: epidemiology and natura history. Allergy Asthma Proc. 31: 365-369.

4. Cox $L$ (2008) Allergen immunotherapy and asthma: efficacy, safety, and other considerations. Allergy Asthma Proc. 29: 580-589.

5. Rank MA, James TCL (2007) Allergen immunotherapy. Mayo Clin Proc 82 1119-1123.

6. Abramson MJ, Puy RM, Weiner JM (2003) Allergen immunotherapy for asthma Cochrane Database Syst Rev 4: CD001186.

7. Frew AJ, Norman PS, Golden DB, Adelman D (2002) Immunoterapia. In: Holgate ST, Church MK, Lichtenstein LM, editors. Alergia. 2nd ed. Madrid: Editions Harcourt; P. 175-185.

8. Till SJ, Francis JN, Nouri-Aria K, Durham SR (2004) Mechanisms of immunotherapy. J Allergy Clin Immunol 113: 1025-1034.

9. Cox L, Nelson H, Lockey R, Calabria C, Chacko T, et al. Allergen immunotherapy : a practice parameter third update. J Allergy Clin Immunol Allergen immunotherapy : a practice parameter third update 127: S1-S55.

10. Frew AJ (1993) Injection immunotherapy. BMJ 307: 919-923.

11. Dursan AB, Sin BA, Oner F, MlsIrllgil $Z$ (2006) The safety of allergen immunotherapy (IT) in Turkey. J Investig Allergol Clin Immunol 16: 123-128.

12. Justicia JL, Barasona MJ, Serrano P, Moreno C, Guerra F (2006) Predicting patients at high risk of systemic reactions to cluster allergen immunotherapy: A pilot perspective observational study. J Investig Allergol Clin Immunol 17 386-392.

13. Serrano $P$, Justicia JL, Sanchez $C$, Cimarra M, Fernández-Távora $L$, et al. (2009) Systemic tolerability of specific subcutaneous immunotherapy with index -of-reactivity -standardized allergen extracts administered using clustered regimines: a retrospective, observational, multicentre study. Ann Allergy Asthma Immunol 102: 247-252.

14. Zeldin Y, Weiler Z, Magen E, Tiosano L, Kidon MI (2008) Safety and efficacy of allergen immunotherapy in the treatment of allergic rhinitis and asthma in real life. IMAJ 10: 869-872.

15. Ullrich D, Thum-Oltmer S, Mussler S, Jaeschke B (2007) Succesful subcutaneous immunotherapy (SCIT) with non modified semi-depot pollen and mite preparations. Allergo J 16: 193-198.

16. Criticos PS, Reed CE, Norman PS, Khoury J, Adkinson NF Jr, et al. (1996) Ragweed immunotherapy in adult asthma. N Eng J Med 334: 501-506.

17. Brockow K, Kiehn M, Riethmuller C, Vieluf D, Berger, et al. (1997) Efficacy of antihistamine pretreatment in the prevention of adverse reactions to Hymenoptera immunotherapy: a prospective randomized placebo-controlled trial. J Allergy Clin Immunol 100: 458-463.

18. Luigi A, Scnna G, Mezzelani P, Pappalardo G (1994) Safety of specific immunotherapy : a retrospective study. J Invest Allergol Clin Immunol 4: 250254.

19. Lockey RF, Nicoara-Kasti GL, Theodoropoulos DS, Bukantz SC (2001) Systemic reactions and fatalities associated with allergen immunotherapy. Ann Allergy Asthma Immunol 87: 47-55.

20. Bernstein DI, Wanner M, Borish L, Liss GM, and the Immunotherapy Committee of the AAAAI (2004) Twelve year survey of fatal reactions to allergen injections and skin testing. 1990-2001. J Allergy Clin Immunol 113: 1129-1136.

21. Borchers AT, Keen CL, Gershwin ME (2004) Fatalities following allergen immunotherapy. Clin Rev Allergy Immunol 27: 147-158.
22. Malling HG, Weeke B (1993) Immunotherapy. Position Paper of the EAACI. Allergy 48: 9-35.

23. Alvarez - Cuesta E, Bousquet J, Canonica GW, Durham SR, Malling HJ, et al (2006) Standars for practical allergen-specific immunotherapy. Allergy 61: 1-20

24. Global Initiative for Asthma. Global Strategy for Asthma Management and Prevention. NHLBI/WHO WorkshopReport.NIH Publication 02-3659. Bethesda. MD: NHLBI, 2002.

25. Dykeewicz M, Fineman S, Skoner D, Nicklas R, Lee R, et al (1998) Diagnosis and management of rhinitis. Complete guidelines of the joint task fore on practice parameters in allergy, asthma, and immunology. Ann Allergy, Asthma Immunol 81: 478-518.

26. Alsamarai AM, Alwan AM, Ahmad AH, Salih MA, Salih JA, et al. (2009) The relationship between asthma and allergic rhinitis in the Iraqi population. Allergology International 58: 549-555.

27. Cook PR, Farias C (1998) The safety of allergen immunotherapy: a literature review. Ear Nose Throat J 378-379, 383-388.

28. Malling HJ (2006) Minimizing the risks of allergen-specific injection immunotherapy. Drug Saf 323-332.

29. Tabar Al, Lizaso MT, Garcia BE, Echechipia S, Olaguibel JM, et al. (2000) Tolerance of immunotherapy with a standardized extract of Aleternaria tenuis in patients with rhinitis and bronchial asthma. J Investig Allergol Clin Immuno 10: $327-333$

30. Hejjaoui A, Dhivert H, Michel FB, Bousquet J (1990) Specific immunotherapy with a standardized Dermatophagoides peteronyssinus extract: IV. Systemic reactions according to immunotherapy schedule. J Allergy Clin Immunol 85: 473-479.

31. Stewart GE 2nd, Lockey RF (1992) Systemic reactions from allergen immunotherapy. J Allergy Clin Immunol 90: 567-578.

32. Moreno C, Cuesto-Herranz JC, Fernandez-Tavora L, Alvarez-Cuesta E Immunotherapy Committee, Sociedad Española de Alergología e Inmunología Clínica (2004) Immunotherapy safety: a prospective multi-centric monitoring study of biologically standardized therapeutic vaccines for allergic diseases. Clin Exp Allergy 34: 527-531.

33. Arifhodzic N, Bhbehani N, Duwaisan AR, Almosawi M, Khan M (2003) Safety of subcutaneous specific immunotherapy with pollen allergen extracts fo respiratory allergy. Int Arch Allergy Immunol 132: 258-262.

34. Amin HS, Liss GM, Bernstein DI (2006) Evaluation of near-fatal reactions to allergen immunotherapy injections. J Allergy Clin Immunol 117: 169-175.

35. Netsi E, Giordano D, Pannofino A, Ferranini A, Tursi A (2002) Safety of inhalant allergen immunotherapy with mass units-standardized extracts. Clin Exp Allergy 32: 1745-1749.

36. Reid MJ, Rockey RF, Turkeltaub PC, Platts-Mills TAE (1993) Survey of fatalities from skin testing and immunotherapy 1985-1989. J Allergy Clin Immunol 92 6-15.

37. Tinkelman DG, Cole WQ 3rd, Tunno J (1995) Immunotherapy: a one yea prospective study to evaluate risk factors of systemic reactions. J Allergy Clin Immunol 95: 8-14.

38. Ventura MT, Giuliano G, Buquicchio R, Accettura F, Carbonara M (2008) Local and systemic reactions occurring during immunotherapy: an epidemiological evaluation and a prospective safety monitoring study. Immunopharmacol Immunotoxicol 30: 153-161.

39. Ragusa FV, Passalacqua G, Gambardella R, Campanari S, Barbieri MM, et al. (1997) Nonfatal systemic reactions to subcutaneous immunotherapy: a 10 year experience. J Investig Allergol Clin Immunol 7: 151-154.

40. Mellerup MT, Hahn GW, Poulsen LK, Malling H (2000) Safety of allergenspecific immunotherapy. Relation between dosage regimen, allergen extract, disease and systemic side effects during induction treatment. Clin Exp Allergy 30: 1423-1429.

41. Taubi E, Kessel A, Blant A, Golan TD (1999) Follow-up after systemic adverse reactions of immunotherapy. Allergy 54: 617-620.

42. Gastaminza G, Algorta J, Audicana M, Fernandez E, Munzo D (2003) Systemic reactions to immunotherapy: influence of composition and manufacturer. Clin Exp Allergy 33: 470-474 
Citation: Alsamarai AM, Alobaidi AHA, Alwan AM, Abdulaziz ZH, Dawood ZM (2011) Systemic Adverse Reaction to Specific Immunotherapy. J Aller Ther 2:111. doi:10.4172/2155-6121.1000111

43. Igea JM, Lazaro M (2002) safety of grass immunotherapy administered in a specialized unit: study of risk factors. Allergol Immunol Clin 17: 16-22.

44. Rank MA, Oslie CL, Krogman JL, Park MA, Li JT (2008)Allergen immunotherapy safety: characterizing systemic reactions and identifying risk factors. Allergy Asthma Proc 29: 400-405.

45. Laurie S (2004) Systemic reactions in multiple aeroallergen rush immunotherapy: two year follow up. J Allergy Clin Immunol 1: S110.

46. Hurst DS, Godon BR, Fornadley JA, Hunsaker DH (1999) Safety of homebased and office allergy immunotherapy: A multicentre prospective study. Otolaryngols Head Neck Surg 121: 553-561.

47. Sanchez I, Garcia JC, Fernandez-Caldas E (2000) Immunotherapy units: a follow up study after 15 months of evolution. J Allergy Clin Immunol 105: S314.

48. Hejjaoui A, Ferrando R, Dhivert H, Michel FB, Bousquet J (1992) Systemic reactions during immunotherapy with standardized pollen extracts. Allergy Clin Immunol 89: 925-933.

49. Rueff F, Wolf H, Schnitker J, Ring J, Przybilla B (2004) Specific immunotherapy in honeybee venom allergy: a comparative study using aqueous and aluminum hydroxide adsorbed preparations. Allergy 59: 389-595.

50. Harvey SM, Laurie S, Hilton K, Khan DA (2004) Safety of rush immunotherapy to multiple allergens in an adult population. Ann Allergy Asthma Immunol 92: 414-419.

51. Goldberg A, Confino-Cohen R (2003) Rush venom immunotherapy in patients experiencing recurrent systemic reactions to conventional venom immunotherapy. Ann Allergy Asthma Immunol 91: 405-410.
52. Jarisch R, Gotz M, Aberer W, Sidl R, Stabel A, et al. (1988) Reduction of side effects of specific immunotherapy by premedicationwith antihistamines and reduction of maximaldosage to $50.000 \mathrm{SQ}-\mathrm{U} / \mathrm{ml}$. Arb Paul Ehrlich Inst Baundersamt Sera Impfstoffe A M 82: 163-175.

53. Nielsen L, Johnsen CR, Mospech H, Pulsen LK, Malling HJ (1996) Antihistamine premedication in specific cluster immunotherapy: a double blind placebo controlled study. J Allergy Clin Immunol 97: 1207-1213.

54. Brockow K, Kiehn M, Riethmuller C, Vieluf D, Berger J, et al. (1997) Efficacy of antihistamine pretreatment in the prevention of adverse reactions to Hymenoptera immunotherapy: a prospective, randomized, placebo controlled trial. J Allergy Clin Immunol 100: 458-463.

55. Reimers A, Hari Y, Muller U (2000) Reduction side effects from ultrarush immunotherapy with honeybee venom by pretreatment with fexofenadine: a double blind, placebo controlled trial. Allergy 55: 484-488.

56. Muller U, Hari Y, Berchthold E (2001) Premedication with antihistamines may enhance efficacy of specific allergen immunotherapy. J Allergy Clin Immuno 107: 81-86.

57. Muller U, Jutel M, Riemers A, Zumkehr J, Huber C, et al. (2008) Clinical and immunologic effects of $\mathrm{H} 1$ antihistamine preventive medication during honeybee venom immunotherapy. J Allergy Clin Immunol 122: 1001-1007.

58. Berchtold E, Maibach R, Muller U (1992) Reduction of side effects from rush immunotherapy with honeybee venom by pretreatment with terfenadine. Clin Exp Allergy 22: 59-65.

59. Herman D, Melac M (1996) Effect of pretreatment with cetirizine on side effects from rush immunotherapy with honeybee venom. Allergy $31: 68$ 